\title{
Trace elements and electrolytes in human resting mixed saliva after exercise
}

Facultad de Medicina, Universidad Complutense, Madrid, Spain

J L Chicharro

R Ureña

A Carvajal

Departamento de Estomatología III (Medicina y Cirugía Buco-Facial), Facultad de Odontología V Serrano

Departamento de Química Analítica, Facultad de Ciencias Químicas

A M Gutierrez

P Fernández-Hernando

Departamento de Ciencias Morfológicas y Fisiología, Universidad Europea de Madrid, Madrid, Spain

A Lucía

Correspondence to: Dr J L Chicharro, Escuela de Enfermería, Fisioterapia y

Podología, Facultad de Medicina, Universidad Complutense de Madrid, 28040 Madrid, Spain.

Accepted for publication 14 January 1999

\author{
J L Chicharro, V Serrano, R Ureña, A M Gutierrez, A Carvajal, P Fernández-Hernando, \\ A Lucía
}

\begin{abstract}
Objectives-Exercise is known to cause changes in the concentration of salivary components such as amylase, $\mathrm{Na}$, and $\mathrm{Cl}$. The aim of this investigation was to evaluate the effect of physical exercise on the levels of trace elements and electrolytes in whole (mixed) saliva.

Methods-Forty subjects performed a maximal exercise test on a cycle ergometer. Samples of saliva were obtained before and immediately after the exercise test. Sample concentrations of $\mathrm{Fe}, \mathrm{Mg}$, Sc, $\mathrm{Cr}, \mathrm{Mn}, \mathrm{Co}, \mathrm{Cu}, \mathrm{Zn}, \mathrm{Se}, \mathrm{Sr}, \mathrm{Ag}, \mathrm{Sb}, \mathrm{Cs}$, and $\mathrm{Hg}$ were determined by inductively coupled plasma mass spectrometry and concentrations of $\mathrm{Ca}$ and $\mathrm{Na}$ by atomic absorption spectrometry.

Results-After exercise, $\mathrm{Mg}$ and $\mathrm{Na}$ levels showed a significant increase $(p<0.05)$ while Mn levels fell $(\mathrm{p}<0.05) . \mathrm{Zn} / \mathrm{Cu}$ molar ratios were unaffected by exercise.

Conclusions-Intense physical exercise induced changes in the concentrations of only three ( $\mathrm{Na}, \mathrm{Mg}$, and $\mathrm{Mn}$ ) of the 16 elements analysed in the saliva samples. Further research is needed to assess the clinical implications of these findings.

(Br F Sports Med 1999;33:204-207)
\end{abstract}

Keywords: trace elements; electrolytes; saliva; exercise

The determination of trace elements in saliva is important in the study of its amylase activity and role in the maintenance of the functional integrity of several tissues of the oral cavity. ${ }^{1-3}$ The significant role of saliva in the maintenance of the structure of teeth, gums, and different epithelial tissues of the mouth are well known. ${ }^{3}$ Analysis of changes in the composition of saliva may help us to understand abnormalities in oral functions such as taste and smell. ${ }^{4-6}$ Several diseases that affect the oral cavity have also been shown to be related to changes in salivary composition. Few investigations have analysed the trace element composition of saliva ${ }^{78}$ and its relation to incidence of dental caries. ${ }^{9-11}$ Borella et $a l^{10}$ found evidence that the $\mathrm{Zn} / \mathrm{Cu}$ molar ratios in whole saliva were significantly reduced in subjects with more than three decayed teeth compared with those with no caries. Duggal et $a l^{9}$ evaluated the relation between changes in trace element levels and incidence of caries in children. They found that the elements $\mathrm{Cu}$ and Fe showed a consistent inverse relation to caries experience. Zaichk and Bagirov ${ }^{11}$ analysed 21 elements in non-stimulated mixed saliva in subjects with different periodontal diseases.
Significant changes in the levels of many of the elements were related to the degree of periodontal tissue involvement.

The study of the physiological responses of salivary glands to exercise has gained attention in recent years. The autonomic nervous system controls the physiological activity of the salivary glands. Both parasympathetic and sympathetic activity stimulates the secretion of saliva. ${ }^{12}$ More specifically, sympathetic stimulation induces changes in the secretion and reabsorption of electrolytes. ${ }^{13}$ It is well documented that sympathetic adrenal activity increases during submaximal incremental exercise. ${ }^{14-16}$ Increased sympathetic activity (estimated by plasma levels of catecholamines) during exercise has been previously associated with an increase in saliva concentrations of $\mathrm{Na}^{+}$and $\mathrm{Cl}^{-} .{ }^{17}$ These findings were later confirmed by a field test. ${ }^{18}$ Changes in the concentration of salivary amylase during exercise have recently been related to attainment of the anaerobic threshold which was associated with increased adrenal sympathetic activity. ${ }^{19}$

Whether intense physical exercise produces changes in the levels of trace elements and electrolytes present in saliva has not been evaluated to date. Besides the fact that changes in the chemical composition of saliva could be hypothetically associated with different periodontal diseases and dental caries, the study of exercise induced changes in salivary composition is of physiological interest per se.

The aim of this investigation was to evaluate the effect of incremental physical exercise on the concentration of 16 trace elements and electrolytes in whole (mixed) saliva.

\section{Methods}

SUBJECTS

Forty healthy young men of different physical characteristics were selected as subjects for the study. Mean (SD) age was 31 (8) years, height $176.54(7.96) \mathrm{cm}$, and body weight 74.16 (9.06) kg. Before being tested, each subject signed an informed consent form in accordance with the regulations of the Complutense University. The participants were also required to complete a medical questionnaire and undergo a physical examination (including a 12 lead electrocardiogram and examination of the oral cavity). Subjects were caries free and pain free, they had healthy gums, and regularly visited the dentist. No subject took vitamin or mineral supplements or medication of any type. All of them followed a similar type of diet, mainly based on complex carbohydrates with a lower content of proteins and lipids. 
EXERCISE TEST

Each subject performed an incremental exercise test to exhaustion to determine maximal oxygen uptake $\left(\mathrm{VO}_{2} \mathrm{MAX}\right)$ and other ergospirometric variables using an automated breath by breath system (CPX; Medical Graphics, St Paul, Minnesota, USA). The test was performed on a cycle ergometer (Ergoline 90; Ergometrics, Barcelona, Spain) at the same time of day (1000-1200 h) after an overnight fast. All the subjects were instructed to follow the same type of carbohydrate-rich diet the day before testing. The exercise consisted of a ramp protocol which started at $0 \mathrm{~W}$ with workload increments of $25 \mathrm{~W} / \mathrm{min}$ at a pedal frequency of 60-80 rpm. All the exercise tests were performed to volitional fatigue or fulfilment of test termination criteria. ${ }^{20}$ Capillary blood samples $(25 \mu \mathrm{l})$ were obtained from fingertips before and immediately after the termination of tests for monitoring of blood lactate concentration $(\mathrm{mmol} / \mathrm{l})$ using an automated lactate analyser (YSI 1500; Yelow Springs Instruments, Yellow Springs, Ohio, USA).

\section{SALIVA COLLECTION AND DETERMINATION OF TRACE ELEMENTS}

Saliva samples were obtained before (resting saliva sample) and immediately after termination of exercise. The time of sample collection was chosen to minimise the influence of circadian variations on salivary flow and composition. ${ }^{21}$ Each subject had been instructed to floss his teeth and thoroughly clean the oral cavity the night before saliva collection. Thirty minutes before the exercise test, each subject was given $400 \mathrm{ml}$ of water to ensure adequate body hydration. The mouth was rinsed with deionised water immediately before saliva collection (resting or after exercise). In addition, each subject was instructed to empty his mouth of "old" saliva before spitting into a sterile container. Samples were kept at $4^{\circ} \mathrm{C}$ and transported to the laboratory in under three hours. Once in the laboratory, samples were centrifuged and the supernatants separated and stored at $-80^{\circ} \mathrm{C}$ for 15 days before preparation. Each sample was diluted 1:250 (40 $\mu$ lo $10 \mathrm{ml}$ ) with Milli-Q water and stored at $4^{\circ} \mathrm{C}$ until the time of analysis. Concentrations of $\mathrm{Fe}$, $\mathrm{Mg}$, Sc, Cr, Mn, Co, Cu, Zn, Se, Sr, Ag, Sb, $\mathrm{Cs}$, and $\mathrm{Hg}$ were determined by inductively coupled plasma mass spectrometry using a model PQ3 ICP-MS (VG Elemental, Winsford CW7 3BX, UK). Nebuliser gas flow rate, ion lens voltages, quadrupole, resolution, and pole bias were optimised using a standard solution containing elements across the mass range from beryllium to uranium at a concentration of $10 \mu \mathrm{g} / \mathrm{l}$. Ca and $\mathrm{Na}$ concentrations were determined using a Perkin-Elmer 2380 atomic absorption spectrometer (Norwalk, Connecticut, USA) equipped with a calcium or sodium hollow cathode lamp and an air/acetylene flame. These elements were determined at wavelengths of 422.7 and $589.0 \mathrm{~nm}$ respectively. The spectral band pass was $0.7 \mathrm{~nm}$. Results are expressed in $\mathrm{mg} / \mathrm{l}$ (ppm).

All the reagents were of analytical grade. High purity Milli-Q water (Millipore, Bedford, Mas- sachusetts, USA) was used in each experiment. Element standard solutions (Spectrosol; BDH, Poole, Dorset, UK) were prepared daily by appropriate dilution of a stock solution (1000 $\mu \mathrm{g} / \mathrm{ml})$. Indium solution $(10 \mu \mathrm{g} / \mathrm{ml})$ was used as the internal standard for the inductively coupled plasma mass spectrometry determinations.

Limits of detection, defined as three times the standard deviation (95\% confidence level) of ten replicate blank determinations, were calculated for the elements analysed. These values were as follows $(\mu \mathrm{g} / \mathrm{l}): 1.5$ for $\mathrm{Mg}, \mathrm{Fe}$, and $\mathrm{Zn}$; 0.2 for $\mathrm{Cr}, \mathrm{Se}, \mathrm{Hg}, \mathrm{Sr}, \mathrm{Mn}$, and Sc; 0.03 for $\mathrm{Co}$, $\mathrm{Sb}, \mathrm{Cs}$, and Ag; 150 for $\mathrm{Ca}$ and 18 for Na. Precision, expressed as relative standard deviation, was less than $3.5 \%$ except in the case of $\mathrm{Se}$ $(9.3 \%)$ and $\mathrm{Cu}(8.4 \%)$.

\section{DATA ANALYSIS}

Once the Kolmogorov-Smirnov test had been applied to establish a Gaussian distribution of results, rest and maximal exercise sample means were compared using Student's $t$ test for paired data. When data for each element did not show a normal distribution, the Wilcoxon test was applied. Results were expressed as mean (SD) and significance was set at $\mathrm{p}<0.05$.

\section{Results}

Table 1 shows the maximal ergospirometric values obtained during the exercise tests.

Table 2 shows the concentrations of the trace elements in saliva at rest and after maximal exercise. Only $\mathrm{Na}, \mathrm{Mg}$, and $\mathrm{Mn}$ concentrations showed variation in response to exercise. The levels of $\mathrm{Na}$ and $\mathrm{Mg}$ increased from 376.32 (340.18) to $836.17(520.34)$ ppm $(\mathrm{p}<0.01)$ and from $9.41(6.19)$ to 11.78 (7.49) $\mathrm{ppm}$

Table 1 Maximal ergospirometric values of the subjects

\begin{tabular}{lc}
\hline Variable & Result \\
\hline $\mathrm{VE}(1 / \mathrm{min})$ & $158.6(33.5)$ \\
$\mathrm{Vo}_{2}(1 / \mathrm{min})$ & $4.0(0.9)$ \\
$\mathrm{Vo}_{2}(\mathrm{ml} / \mathrm{kg} / \mathrm{min})$ & $56.1(9.9)$ \\
$\mathrm{RER}$ & $1.3(0.1)$ \\
$\mathrm{HR}(\mathrm{bpm})$ & $187(15)$ \\
$\mathrm{BLa}(\mathrm{mM} / \mathrm{l})$ & $13.5(3.3)$ \\
Power output (W) & $358.6(67.9)$
\end{tabular}

Values are mean (SD).

Abbreviations: VE, pulmonary ventilation; $\mathrm{Vo}_{2}$, oxygen uptake; $\mathrm{RER}$, respiratory exchange ratio; $\mathrm{HR}$, heart rate; $\mathrm{BLa}$, blood lactate.

Table 2 Concentrations $(\mathrm{mg} / \mathrm{l})$ of trace elements and electrolytes in whole saliva

\begin{tabular}{lccl}
\hline Element & Rest & Post-exercise & $p$ Value \\
\hline $\mathrm{Ca}$ & $129.92(98.22)$ & $110.28(59.82)$ & $\mathrm{NS}$ \\
$\mathrm{Fe}$ & $4.73(2.64)$ & $4.51(2.13)$ & $\mathrm{NS}$ \\
$\mathrm{Mg}$ & $9.41(6.19)$ & $11.78(7.49)$ & 0.05 \\
$\mathrm{Na}$ & $376.32(340.18)$ & $836.17(520.34)$ & 0.01 \\
$\mathrm{Sc}$ & $0.12(0.12)$ & $0.16(0.32)$ & $\mathrm{NS}$ \\
$\mathrm{Cr}$ & $0.23(0.20)$ & $0.23(0.27)$ & $\mathrm{NS}$ \\
$\mathrm{Mn}$ & $1.99(2.04)$ & $1.40(1.69)$ & 0.05 \\
$\mathrm{Co}$ & $0.03(0.03)$ & $0.02(0.03)$ & $\mathrm{NS}$ \\
$\mathrm{Cu}$ & $0.18(0.28)$ & $0.19(0.31)$ & $\mathrm{NS}$ \\
$\mathrm{Zn}$ & $8.72(7.55)$ & $8.11(13.91)$ & $\mathrm{NS}$ \\
$\mathrm{Se}$ & $0.91(1.34)$ & $0.64(0.84)$ & $\mathrm{NS}$ \\
$\mathrm{Sr}$ & $1.35(1.45)$ & $1.15(2.08)$ & $\mathrm{NS}$ \\
$\mathrm{Ag}$ & $0.04(0.06)$ & $0.04(0.05)$ & $\mathrm{NS}$ \\
$\mathrm{Sb}$ & $0.05(0.04)$ & $0.05(0.05)$ & $\mathrm{NS}$ \\
$\mathrm{Cs}$ & $0.02(0.02)$ & $0.01(0.01)$ & $\mathrm{NS}$ \\
$\mathrm{Hg}$ & $1.36(2.46)$ & $1.07(1.33)$ & $\mathrm{NS}$ \\
$\mathrm{Zn} / \mathrm{Cu}$ ratio & $50.33(12.86)$ & $60.56(46.28)$ & $\mathrm{NS}$ \\
\hline
\end{tabular}

Values are mean (SD). 
$(\mathrm{p}<0.05)$ respectively. In contrast, $\mathrm{Mn}$ levels fell from 1.99 (2.04) to 1.40 (1.69) $\mathrm{ppm}$ $(\mathrm{p}<0.05)$ after the exercise test. $\mathrm{Zn} / \mathrm{Cu}$ molar ratios were estimated in 10 of the subjects; no significant difference was found between the values found at rest and after exercise (50.33 (12.86) v 60.56 (46.28), $\mathrm{p}>0.05)$.

\section{Discussion}

The change in concentration of some of the trace elements in saliva as a consequence of incremental physical exercise was the most significant finding. After the exercise test, $\mathrm{Na}$ and $\mathrm{Mg}$ concentrations showed a significant increase and Mn levels fell. Ergospirometric data confirmed that the exercise performed by subjects was intense and that criteria for $\mathrm{VO}_{2} \mathrm{MAX}^{22}$ had been met.

Although $\mathrm{Zn}, \mathrm{Cu}, \mathrm{Fe}$, and $\mathrm{Mn}$ concentrations before the exercise test were comparable with those observed by Dugall et al in children with dental caries, the resting levels of most of the salivary trace elements were in overall agreement with those reported for the healthy adult. ${ }^{23}$ Nevertheless, the high degree of variability between subjects in the levels of trace element in resting saliva reported here has also been previously described. ${ }^{10}$

The increase in $\mathrm{Na}$ concentration attributed to physical exercise is in accordance with the findings of several authors ${ }^{17182425}$ and may be related to increased sympathetic activity during exercise. Indeed, sympathetic stimulation of salivary glands induces a decrease in salivary flow and an increase in the concentration of some of its constituents such as $\mathrm{Na} .{ }^{17}$ There are no directly comparable reports, however, to confirm the increase in $\mathrm{Mg}$ and decrease in $\mathrm{Mn}$ levels or the behaviour of the other trace elements in saliva after exercise. Furthermore, the possible explanations for the reported changes in $\mathrm{Mg}$ and $\mathrm{Mn}$ concentrations are speculative, as little is known about the site of secretion of either of these trace elements in the salivary glands. It may be hypothesised that the exercise induced decrease in salivary flow rate may lead to a low supply of capillary blood to the salivary glands which, in turn, may alter their reabsortive and secretory mechanisms. Such phenomena could be partly responsible for the increases in salivary concentrations of $\mathrm{Na}$ and $\mathrm{Mg}$ that may occur during exhaustive exercise. ${ }^{25}$ Further, the increased levels of these two trace elements could be indicative of the $\beta$-adrenoceptor dependent ductal regulation of $\mathrm{Na}$ and $\mathrm{Mg}$ reabsorption. It is well known that saliva is not simply a transudate of blood plasma but that it also reflects the metabolic activity of the different salivary glands. ${ }^{6}$ The use of non-stimulated mixed saliva does not permit specification of the changes occurring in each salivary gland in response to physical exercise. Furthermore, interpretation of our findings is limited by the fact that we did not measure salivary flow rate. Indeed, salivary flow - that is, from the parotid gland-may be altered with exertion ${ }^{21}$ and could, at least partially, account for some of the exercise induced changes in salivary composition.
Several authors ${ }^{9-11}$ have associated changes in the concentrations of trace elements in saliva with the incidence of periodontal disease and dental caries in different population groups. Borella et $a l^{10}$ showed during at least one year of follow up that $\mathrm{Zn} / \mathrm{Cu}$ molar ratios were lower in subjects with decayed teeth. In the present investigation, exercise did not produce significant modifications to this ratio in the short term. Whether continuous exercise over the year would induce significant changes in $\mathrm{Zn}$ and $\mathrm{Cu}$ levels and/or a greater incidence of caries in subjects who exercise regularly is not known. Zaichk and Bagirov ${ }^{11}$ found that adults with a greater incidence of periodontal disease showed increased resting salivary concentrations of $\mathrm{Fe}, \mathrm{Sc}, \mathrm{Mn}, \mathrm{Cr}, \mathrm{Co}$, $\mathrm{Cu}, \mathrm{Se}, \mathrm{Ag}$, and $\mathrm{Hg}$ and reduced concentrations of $\mathrm{Zn}$. Based on the present increase in $\mathrm{Na}$ and $\mathrm{Mg}$, and decrease in Mn levels, it seems that physical exercise does not produce a short term change in the composition of saliva with, in turn, no greater risk of periodontal disease or caries. Whether regular training produces significant changes in salivary composition requires investigation. Duggal et $a l^{9}$ found that the concentrations of $\mathrm{Cu}$ and $\mathrm{F}$ showed a consistent inverse relation to the incidence of caries in children, but the elements $\mathrm{Zn}, \mathrm{Fe}$, and $\mathrm{Mn}$ did not. In this study, there was no short term change in $\mathrm{Cu}$ concentration after exercise. Loss of tooth mineral ${ }^{26}$ has been related to a decrease in the $\mathrm{pH}$ of saliva, although some authors ${ }^{2125}$ report no changes in $\mathrm{pH}$ attributable to exercise. However, the effect of exercise on $\mathrm{pH}$ was not studied in this investigation.

It may be concluded that intense physical exercise produced significant change in the saliva concentrations of only three of the 16 elements analysed. It is felt that future investigations should focus on whether significant modification in salivary composition takes place in subjects who exercise regularly and whether these putative changes could lead to a greater incidence of periodontal disease, caries, and/or disorders of oral function.

This investigation was funded by a grant from the Universidad Complutense, Madrid. The authors would like to thank Ana Burton for the translation of the manuscript.

1 Orstavik D, Kraus FW. The acquired pellicle: immunofluorescent demonstration of specific proteins. F Oral Pathol 1973;2:68-76

2 Rolla G, Ciardi JE, Bowen WH. Identification of IgA, IgG, lysozyme, albumin, alpha-amylase and glucosyltransferase in the protein layer adsorbed to hydroxyapatite from whole saliva. Scandinavian fournal of Dental Research 1983;91: saliva. Scan $186-90$.

3 Hay DI. Cariology today. Basel: Karger, 1984:98-108.

4 Henkin RI, Schechter PJ, Hoye RC, et al. Idiopathic hypogeusia with dysgeusia, hyposmia, and dysosmia. A new syndrome. $\mathcal{F} A M A$ 1971;217:434-40.

5 Shatzman AR, Henkin RI. Gustin concentration changes relative to salivary zinc and taste in humans. Proc Natl Acad Sci USA 1981;78:3867-71.

6 Olmez I, Gulovalli MC, Gordon GE, et al. Trace elements in human parotid saliva. Biol Trace Elem Res 1988;17:259-70.

7 Dreizen S, Levy BM. Comparative concentrations of selected trace metals in human and marmoset saliva. Arch Oral Biol 1970;15:179-88.

8 Schamschula RJ, Adkins BL, Barmes DE, et al. Caries experience and the mineral content of plaque in a primitive population in New Guinea. 7 Dent Res 1977;56:C62-70.

9 Duggal MS, Chawla HS, Curzon ME. A study of the relationship between trace elements in saliva and dental relationship between trace elements in saliva and
caries in children. Arch Oral Biol 1991;36:881-4. 
10 Borella P, Fantuzzi G, Aggazzotti G. Trace elements in saliva and dental caries in young adults. Sci Total Environ and dental caries

11 Zaichk VE, Bagirov ShT. The chemical element content of mixed unstimulated saliva in periodontal diseases. Stomatologiia (Mosk) 1994;73:8-11.

12 Schneyer CA, Hall HD. Autonomic pathways involved in sympathetic-like action of pilocarpine on salivary composition. Proc Soc Exp Biol Med 1966; 121:96-100.

13 Denniss AR, Schneyer LH, Sucanthapree C, et al. Actions of adrenergic agonists on isolated excretory ducts of submandibular glands. Am f Physiol 1978;235:F548-56.

14 Gleim GW, Zabetakis PM, Deponquale EE, et al. Plasma osmolarity, volume and renin activity at the "anaerobic threshold". F Appl Physiol 1984;52:991-4.

15 Lehmann M, Schmid P, Keul J. Plasma catecholamines and blood lactate accumulation during incremental exhaustive exercise. Int I Sports Med 1985;6:78-81.

16 Stainsby WN, Summers C, Andrew GM. Plasma catecholamines and their effect on blood lactate and muscle lactate output. F Appl Physiol 1984;57:321-5.

17 Chicharro JL, Legido JC, Álvarez J, et al. Saliva electrolytes as a useful tool for anaerobic threshold determination. Eur f Appl Physiol 1994;68:214-18.
18 Chicharro JL, Calvo F, Álvarez J, et al. Anaerobic threshold in children: determination from saliva analysis in field tests. Eur 7 Appl Physiol 1995;70:541-4.

19 Calvo F, Chicharro JL, Bandres F, et al. Anaerobic threshold determination with analysis of salivary amylase. Can $\mathcal{F} A p p l$ Physiol 1997;22:553-61.

20 American College of Sports Medicine (ACSM). Guidelines for exercise testing and prescription (6th ed). Philadelphia: Lea \& Febiger, 1986.

21 Dawes C. The effects of exercise on protein and electrolyte secretion in parotid saliva. $\mathcal{F}$ Physiol 1981;320:139-48.

22 Jones NL, Mccartney N, Graham T, et al. Muscle performance and metabolism in maximal isokinetic cycling at slow and fast speeds. F Appl Physiol 1985;59:132-6.

23 Zaichik VE, Bagirov ST. The chemical element content of mixed unstimulated saliva from a healthy subject. Stomatologiia (Mosk) 1991;70:14-17.

24 Salminen S, Konttinen A. Effect of exercise on $\mathrm{Na}$ and $\mathrm{K}$ concentrations in human saliva and serum. F Appl Physiol 1963;18:812-14.

25 Ljungberg G, Ericson T, Ekblom B, et al. Saliva and marathon running. Scand $\mathcal{F}$ Med Sci Sports 1997;7:214-19.

26 Milosevic A. Sports drinks hazard to teeth. Br f Sports Med 1997;31:28-30.

\section{Take home message}

Intense physical exercise - that is, incremental test to exhaustion - induces acute changes in the salivary concentrations of only a few trace elements/electrolytes such as $\mathrm{Na}, \mathrm{Mg}$, and $\mathrm{Mn}$. Further research may determine whether salivary composition is chronically modified in subjects who exercise regularly.

\section{Commentaries}

Few studies have investigated the effect that exercise has on saliva and thus on general dental health in sports people. This paper found no change in resting whole salivary concentrations in 13 out of 16 trace elements before and after strenuous exercise. The subjects did not regularly engage in sports and the authors rightly point out that the results could alter with regular training. The increase in $\mathrm{Na}$ and $\mathrm{Mg}$ needs careful interpretation as flow rates were not measured or controlled for and the relative contribution to whole saliva from different glands may be altered by exercise. The current literature on the influence of exercise on salivary $\mathrm{Na}$ is thus conflicting, although different methods could account for the different results. Perhaps of greater interest for future research is the bicarbonate concentration before, during, and after exercise as this will influence both caries and acid erosion.

A MILOSEVIC

Liverpool

The object of this paper is to establish a relation between trace element concentration of human mixed saliva and physical exercise. The authors have justified the aims on the basis of possible implications for dental disease, namely dental caries and periodontal disease. The study is worth while because it has established the concentrations of a large number of trace elements in saliva, which would be a useful reference for other researchers. However, guarded conclusions should be drawn about its clinical relevance from a dental prospective. Although most of the discussion is based on the possible relation between the trace elements and dental disease, it should be remembered that the study was a snapshot in time of the concentration of these elements related to exercise. To establish clinical significance, the trace element concentrations should be studied in subjects who exercise on a regular basis, such as athletes, and related to the prevalence of dental disease in that population.

M S DUGGAL Leeds 